\title{
Design without thermal bridges
}

\author{
Irina Maltseva ${ }^{1, *}$, Aleksandr Elokhov ${ }^{2}$, Konstantin Tkachuk ${ }^{1}$, and Kseniia Maltceva ${ }^{1}$ \\ ${ }^{1}$ URFU, Department of Civil Engineering, 620002 Yekaterinburg, Russia \\ ${ }^{2}$ Institute of Passive house, Production Department, 117405 Moscow, Russia
}

\begin{abstract}
The main focus of the article is on the quality design and implementation of the thermal insulation of buildings. Shells of buildings consist not only of conventional structures (wall, roof, ceiling), but also of edges, corners, joints and places of disruption of the outer thermal insulation shell integrity (due to through passage of pipelines, ventilation ducts and etc.). In all these places, heat losses are generally increased in comparison with conventional surfaces. Some of them are easily taken into account by calculation, using a special method proposed by the authors. Other thermal bridges due to unfavorable structural details can be avoided by observing the rules and recommendations that are classified and discussed in detail in this article.
\end{abstract}

\section{Introduction}

At the present time, the efficient use of energy is a worldwide concept. Many countries, even those with large reserves of natural resources such as natural gas, oil, etc., have realized the importance of preserving their resources so that they can be used for a longer period. Energy consumption is a priority problem in the domestic and world construction. Energy is consumed for various purposes, for example, heating hot water, using household appliances, but the dominant are the costs of heating in winter and air conditioning in the summer, which is usually about $70 \%$ of the total energy consumption. Most of this energy is obtained from fossil fuels, and its consumption leads to the corresponding emissions of pollutants. In most cases, this can be avoided through the implementation of energy efficient technologies and energy conservation measures. To this end, the EU has developed a program to increase energy efficiency by $20 \%$ until 2020 . Various studies [1] confirm that this goal is achievable. Currently, the main direction of Russia's government policy are: conducting energy audits, developing energy efficiency standards for certain types of products, revising old standards and adopting new standards for existing and newly constructed buildings for various purposes, promoting energy efficiency principles [2]. In this regard, the issue of building energy-efficient buildings in Russia is becoming one of the key, and the problem of rational use of energy resources is becoming increasingly important. An innovative and very strict policy in terms of energy consumption in buildings for various purposes (for example, the Directive on the construction of buildings with zero energy consumption) has contributed to the development of high-level competence in the

\footnotetext{
* Corresponding author: i.n.maltceva@urfu.ru
} 
development of energy-efficient buildings [3]. Today, there is an opportunity, both in Russia and in European countries, to design and construct buildings with a sufficiently low energy consumption, which is achieved by a correct solution of the thermal envelope of buildings and their ventilation systems. In the article we will consider the rules and recommendations for the design of thermal protection of buildings.

\section{Thermal protection of building}

The main principles of good thermal insulation are based on the need to determine closed thermal (heat-insulating) shell covering of the comfort zone. This insulation should be high quality and fit tightly without gaps and openings. It is also necessary to avoid complex forms of the outer thermal insulation of the building [4,5]. All rooms, which temperature in winter should be $+21^{\circ} \mathrm{C}$, are inside this shell, which is interrupted only in the places where the windows are installed and has high thermal insulation characteristics throughout the circuit. The minimum thickness of the insulation, with a coefficient of thermal conductivity $\lambda=0.04 \mathrm{~W} /(\mathrm{m} \cdot \mathrm{K})$, in the Urals region should be of about $200 \mathrm{~mm}$ in every point of the thermal insulation shell. In most cases it is desirable even to improve the heat insulation of opaque external building elements up to $\mathrm{R}_{0}=10 \mathrm{~m}^{2} \cdot \mathrm{K} / \mathrm{W}$, which corresponds to the equivalent thickness of the effective insulation about $400 \mathrm{~mm}$. In the future, more and more vacuum panels will be used, with the use of which a high thermal insulation effect is possible with relatively small wall thicknesses. Complex designs must be avoided: they are not practical and mainly expensive. Thermal insulation shell can be designed to be practical and very simple[6]. Observance of the four rules given below helps to reduce the heat loss caused by thermal bridges $[7,8]$.

The first rule is avoiding thermal bridges is to exclude opening holes in the outer shell of buildings unless extreme necessity.

The second rule is the laying of thermal insulation. If it is not possible to avoid holes in the heat-insulating layer, then it is necessary to maximize the heat transfer resistance of the enclosure as a whole, for example, to use porous concrete in combination with mineral wool insulation.

The third rule is tight junction (for joints). The location of the insulation in the joints of building elements and structures must be without empty spaces, i.e. joint must be completely isolated.

The fourth rule relates to the geometry of the building: it is necessary, if possible, to choose edges with obtuse angles (more than $90^{\circ}$ ).

Due to careful design and conscientious implementation, it is possible to significantly reduce the heat loss caused by thermal bridges.

\section{Thermal bridges}

This title hides a very important concept for any civil engineer, as well as a person who wants his house to be comfortable and cozy. Any erected building, especially in our Ural region, should be warm. Thermal bridges are such areas in the building structure, through which there is a large heat transfer. Shells of buildings consist not only of conventional structures (wall, roof, ceiling), but also of edges, corners, joints and places of disruption of the outer thermal insulation shell integrity (due to through passage of pipelines, ventilation ducts and etc.). In all these places, heat losses are generally increased in comparison with conventional surfaces. When designing the thermal insulation shell of energy-efficient buildings, it is necessary to carefully develop and calculate all the nodes at the design stage and during the construction. 
When choosing materials for the thermal shell coefficients $\Psi$ (psi) and $\chi$ (chi) are controlled. Their values (in external dimensions) should be $\Psi<0.01 \mathrm{~W} /(\mathrm{m} \cdot \mathrm{K})$ and $\chi<0.01$ $\mathrm{W} / \mathrm{K}$, or the following condition must be fulfilled: the sum of the specific transmission heat losses through the outer shell of the building without thermal bridges should be less than the amount of losses with taking into account the thermal bridges. That means, the sum of all heat losses from thermal bridges is less than zero. This is quite possible, because all areas of the filler structures for calculation in PHPP are taken from the outside dimensions.

Specific transmission loss

$$
H_{T}=\sum f_{j} A_{j} U_{j}+\sum f_{j} \Psi_{j} I_{j}+\sum f_{j} X_{j}
$$

Where:

$\sum f_{j} A_{j} U_{j}=$ specific transmission loss through the outer shell

$\sum f_{j} \Psi_{j} I_{j}=$ specific transmission loss through linear thermal bridges (TB)

$\sum f_{j} X_{\mathrm{j}}=$ specific transmission loss through point TB

\section{Design without thermal bridges}

$$
H_{\text {norm }}=\sum f_{j} A_{j} U_{j} \geq H_{T}
$$

The appearance of particular thermal bridges can hardly be avoided: for example, increased heat loss along the outer edge of the building. These and other so-called "geometric" thermal bridges can be easily taken into account by using the "Passive House Planning Package" (PHPP) program, which allows to fully account for heat flows through all constructions and structural layers of the thermal insulation shell [9]. According to the PHPP method, heat losses are calculated for the external surfaces of the corresponding structures. Losses should be taken into account for linear heat transfer coefficients $\Psi>0.01$ $\mathrm{W} /(\mathrm{m} \cdot \mathrm{K})$, and it is possible to conduct a full account of all heat losses.

To do this, there are coefficients that take into account the heat loss through linear thermal bridges and relate to the external dimensions, $\Psi$. They can be entered in the "Areas" worksheet, which is in the PHPP program (Fig. 1).

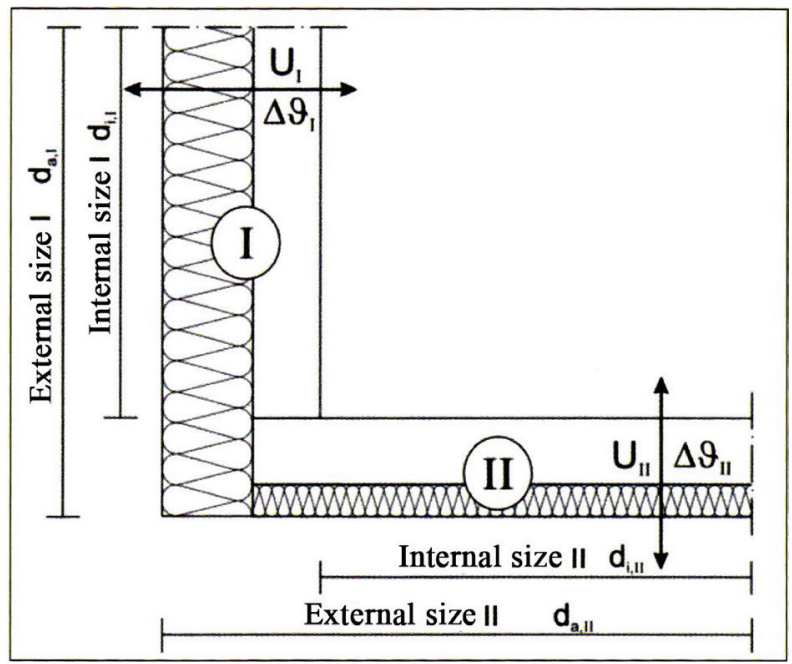

Fig. 1. Dimensions of building elements for calculation with taking into account thermal bridges.

Other thermal bridges are caused by unfavorable structural details: for example, if the balcony plate is not thermally separated from the concrete ceiling (it is better to use a 
separate foundation for the balconies), the additional heat loss of this "cold rib" becomes significant. The most unreliable joints are in connections between the wall with ceilings and roofing, esconson of windows, places under the windowsills, exits to the balcony or veranda. Such constructive thermal bridges in the thermal insulation shell should be avoided, especially in passive buildings. In addition to poorly connected material, the cause of "cold bridges" may be insufficient thickness of the thermal insulation layer.

Thermal bridges in the existing building lead to:

- the decrease in indoor temperature during the cold seasons and overheating of premises in hot seasons;

- the formation of condensate on the inner surface of the filler structure;

- the significant increase in the expenditure of resources for heating the house;

- the increased probability of dampness and mold on the inner walls of the house (Fig.2);

- the development of harmful bacteria, and this is dangerous for human health.
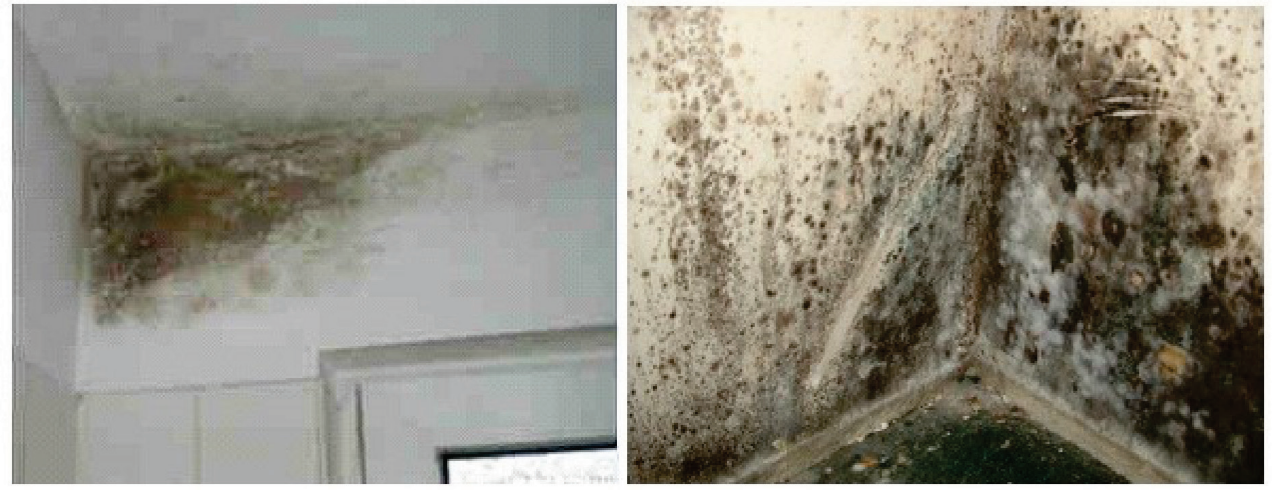

Fig. 2. Dampness, fungus and black mold on walls and ceilings.

It is very hard to remove mold. In most cases, changing the wallpaper or repainting the wall does not lead to anything, mold gets out and again takes its place. Treatment with special addings is needed to completely remove the mold from this place. And the cold bridges themselves are usually removed by implementation of additional thermal insulation. To control the mold and dampness it is important to look for problem areas, check the internal surfaces to understand where there is a heat outflow. Thermal imager helps a lot to check this. On the thermogram in the corners there is an intense heat outflow that cools the wall and air inside the room (Fig. 3).

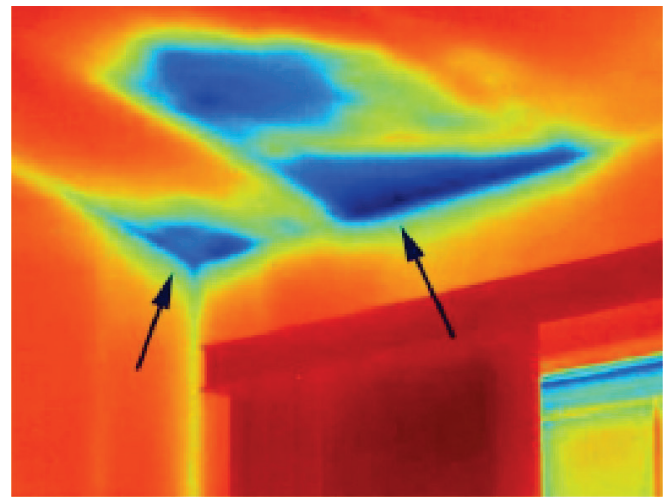

Fig. 3. Thermogram of the joint of the wall and the ceiling, obtained with the thermal imager. 
Such buildings need reconstruction and, most importantly, the elimination of thermal bridges. The main thing is to construct continuous thermal insulation shell. This requirement seems obvious, but in fact it is not always fulfilled when building a house. And for energy-efficient buildings, it is of particular importance, since the formation of a large number of linear thermal bridges calls into question the whole idea. To determine the level of criticality of each thermal bridge, special calculations are made (Fig. 4).

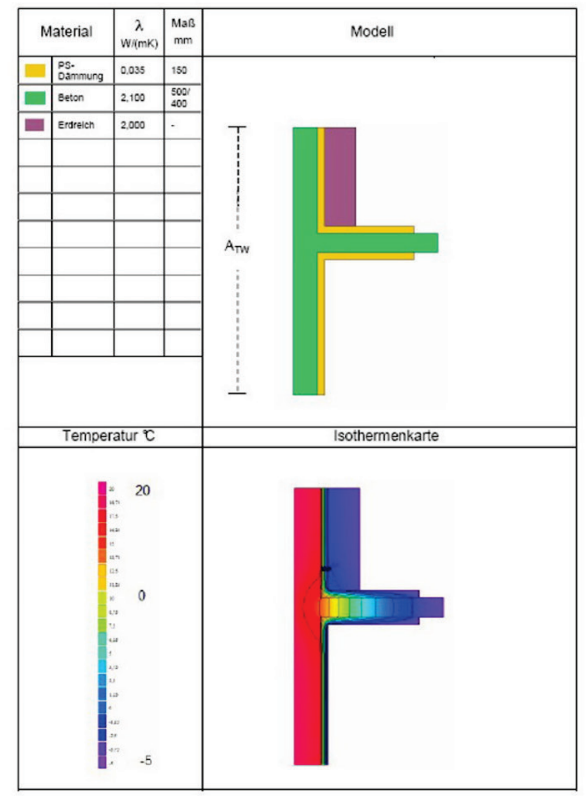

\begin{tabular}{|l|c|c|c|}
\hline \multicolumn{4}{|l|}{ Ergebnisse } \\
\hline $\begin{array}{l}\text { Bezugstemperaturdifferenz des } \\
\text { Wärmedurchgangskoeffizienten }\end{array}$ & $\Delta \Theta$ & 30 & $K$ \\
\hline linearer Wàrmedurch gangskoeffizient & $\Psi_{A W}$ & 0,305 & $\mathrm{~W} /(\mathrm{mK})$ \\
\hline minimale Innentemperatur bei $5^{\circ} \mathrm{C} /-5^{\circ} \mathrm{C}$ & $\Theta_{\min }$ & $19,4 / 18,4$ & ${ }^{\circ} \mathrm{C}$ \\
\hline
\end{tabular}

Stairs wall to the basement ceiling; insulation on the external side $(10 \times 200 \mathrm{~cm})$

10_KD-TW_insulation outside

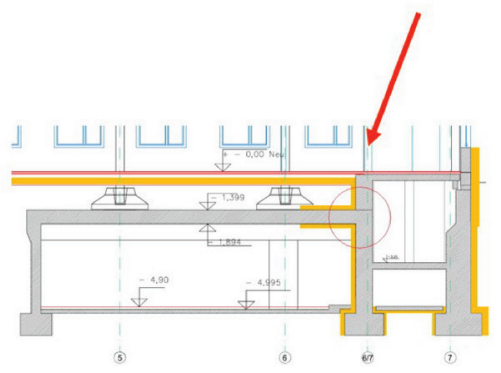

Fig. 4. An example of calculation of a geometric thermal bridge during the reconstruction of an old building according to the passive house standard.

\section{Conclusion}

To sum up, it is necessary to emphasize that the construction of new energy efficient buildings or the reconstruction of existing without thermal bridges begins at the design stage. The basis is a complex approach. All parameters are determined by the calculation method «Passive House Planning Package» (PHPP). Closed thermal insulation shell is obligatory element throughout the entire contour of the building with an increased thickness of insulation, especially in the Ural-Siberian region of Russia. Certified materials designed specifically for the passive house allow to ease the work of designers and protect them from unnecessary errors [10]. Most manufacturers of building materials and products, as well as producers of engineering equipment, have developed together with the staff of the Passive House Institute a whole base of certified goods [11]. Following these recommendations, we will improve the quality of people's lives, we will get multi-comfortable human habitat without harmful bacteria, fungus and mold.

\section{References}

1. V. Bianco, F. Scarpa, L.A. Tagliafico, Energy Conversion and Management 87, 754764 (2014)

2. Roadmap. EU-Russia Energy Cooperation until 2050 (March 2013) 
3. T. Maltby, Energy Policy 55,435-444 (2013)

4. V. Gagarin, ABOK, 1-3 (2009)

5. S.G. Sheina, D.K. Upennikov, Internet-journal "NAUKOVODENIE" 7, 3 (2015)

6. M.M. Brodach, N.V. Shilkin, VIII International Scientific Conference «Walls and facades. Actual problems of thermophysics»: collection of materials, 191-196 (2003)

7. V. Feist, Basic provisions for the design of passive houses (Translation from German with additions edited by A.E. Elokhov), KONTI PRINT, 144 (2015)

8. R. Perminov, I. Maltceva, N. Kaganovich, A. Yelohov, AMM 725-726, 1389-1394 (2015)

9. Available on http://www.passiv-rus.ru

10. Schöck Design Guide: Solutions to Prevent Thermal Bridging (June 2014)

11. Passive House Database. Available on

http://www.passivhausprojekte.de/index.php?lang=en 